\title{
Enabling peer-to-peer electricity trading
}

\author{
Jordan Murkin \\ Department of Computer Science \\ University Of Leicester \\ Leicester, UK \\ Email: jpm45@le.ac.uk
}

\author{
Ruzanna Chitchyan \\ Department of Computer Science \\ University Of Leicester \\ Leicester, UK \\ Email: rc256@le.ac.uk
}

\author{
Alastair Byrne \\ EDF Energy R\&D UK Centre \\ EDF Energy \\ Hove, UK \\ Email: alastair.byrne@edfenergy.com
}

\begin{abstract}
Due to the recent advances in household-level renewable electricity generation technology, a new type of market based on peer-to-peer $(\mathrm{P} 2 \mathrm{P})$ electricity trading between households will emerge. This poster presents a technical platform which will enable such a market to function.
\end{abstract}

Index Terms-Blockchain, peer-to-peer electricity, smart grid, microgeneration.

\section{INTRODUCTION}

Electricity production and supply has traditionally been, and still remains, a majority centralised system, with Major Power Producers (MPPs) making up $94 \%$ of electricity production [1]. In this system, MPPs generate electricity that is fed through the grid to individual households. However, this situation has already begun to change with the increased adoption of microgeneration [2], i.e., production of heat or electricity on a small, local scale, with domestic energy producers taking a much more active role.

Instead of the current centralised system, we could see consumers with microgeneration selling their electricity on a peerto-peer (P2P) network to other individuals or organisations on the grid. Here, households are more than prosumers, as while they do produce and consume their own electricity, they also sell it to others on a free market. Essentially, households become small energy suppliers, hereafter referred to as household or domestic suppliers.

This poster provides a deeper insight into such a P2P market and outlines a design of a technical platform to support it.

\section{Changes to The ElECTRICITy SyStem}

Because of the small amounts of electricity produced by domestic suppliers and their likely supply intermittency, due to their renewable-based production, there would have to be significant differences between the current system of energy supply and consumption and the one envisioned with a greater installed capacity of microgeneration:

- Instead of sourcing their electricity from a single supplier, consumers would buy and sell electricity across an open market, essentially swapping their energy supplier on a minute-by-minute basis.

- Households will be able to buy electricity based on a their own personal preference, whether it be distance from the generator, type of generation, or just to buy at the best price.
To enable this, a P2P trading platform (hereafter referred to as the platform) would need to be created in which households could market their electricity exports for other households to buy. Once the platform is in place, optimisation methods could be developed to automate the trading process to either increase monetary benefits, support local generators, or even to smooth load curves on the grid as a whole.

Electricity transmission causes energy losses, and the further electricity travels, the more of it is lost [3]. If the true cost of losses were reflected in sale price then generators would be able to offer a better price to nearby customers. This could benefit both the environment and customers. Thus, the key benefits for domestic suppliers using this platform are:

- Ability to exercise independent choice on the purchase and sale of electricity according to their personal preferences and needs;

- Added monetary benefits through optimising for the most favourable energy transactions at any given time;

- Increased independence from the grid in case of power supply issues from MPPs.

\section{REQUIREMENTS OF A PEER-TO-PEER MARKET}

In order to develop and enable P2P trading of electricity, a number of steps need to take place:

- Microgenerated electricity needs to be verified, with the generation time and amount recorded. This is required, as the price of electricity varies over time based on supply and demand.

- Each unit of electricity must only ever be represented by one token on the network.

- Trades must be traceable and auditable to enable electricity suppliers (domestic and otherwise) to accurately calculate bills.

\section{PlatForm DESIGN}

We have selected blockchain technology as the solution of choice for the platform, as it provides a decentralised, distributed ledger in which all transactions are immutably recorded. It relies on cryptography to ensure transactions are secure, authenticated and accurate [4]. Thus, it could support the delivery of an energy trading mechanism that meets the above requirements.

The platform is comprised of a number of components that work together to enable a decentralised, open market. These 
Peer-to-peer electricity trading platform

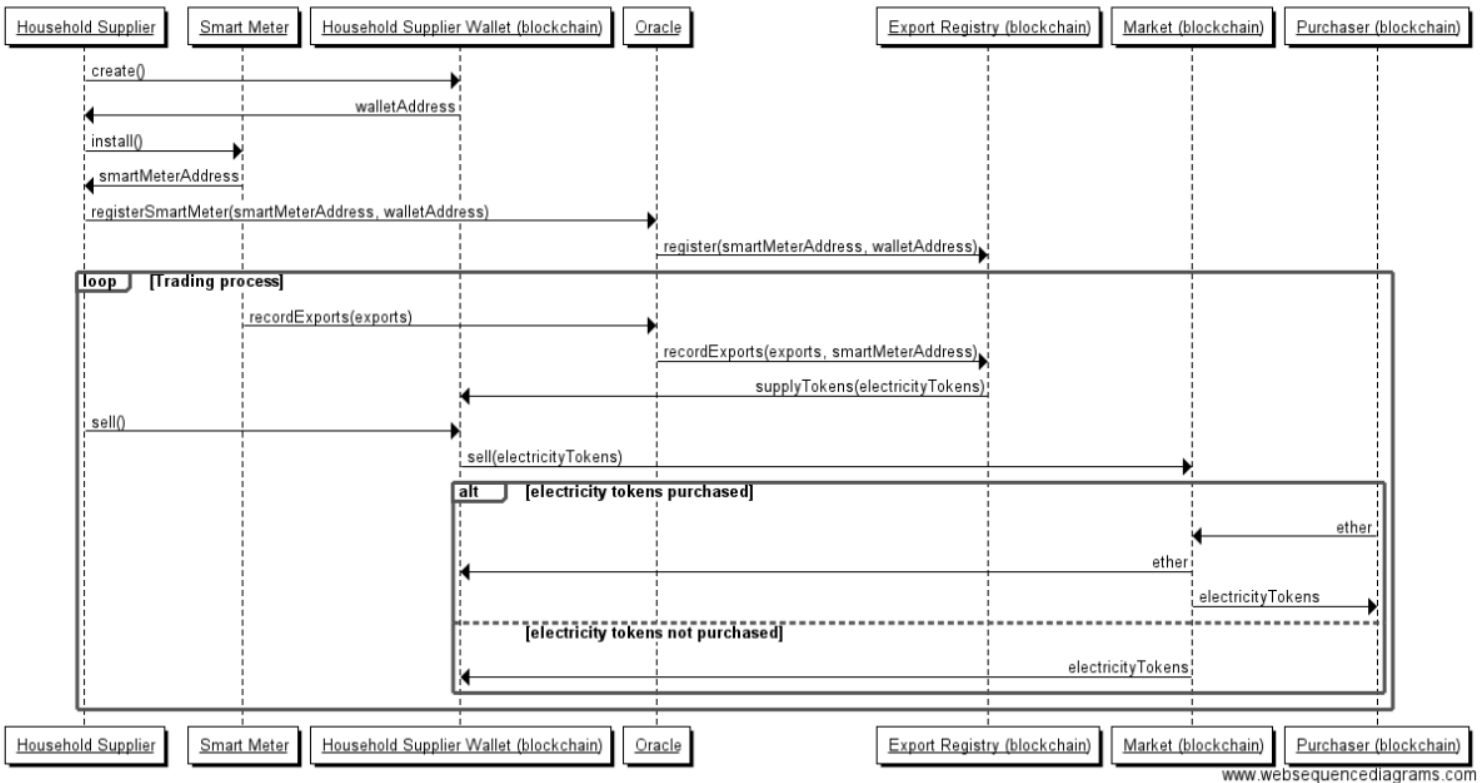

Fig. 1. Trading process sequence diagram

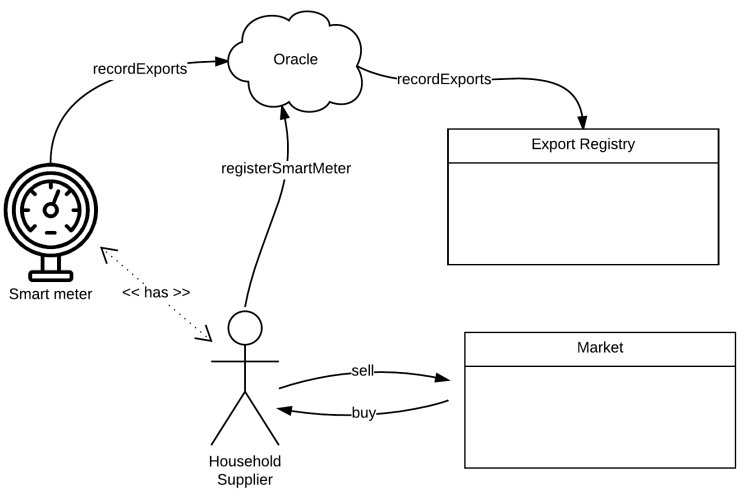

Fig. 2. Platform structure from a household supplier's perspective

components and how they communicate with one another are shown in Fig. 1 and Fig. 2.

Here, a household supplier is a micro-generator that produces electricity, uses some of its own product, sells excess and purchases electricity on the market when its own generation falls short. Each household supplier has a smart meter installed which records electricity consumption and generation data. This data is then passed to an oracle that manages the movement of content from the real-world on to the blockchain. In this case, the oracle tokenises their electricity generation and associates it to a household supplier's address on the blockchain ledger. This tokenisation would allow the generation to be represented as a sub-currency on the network so it could be traded (e.g., 1 token per kWh generated). For the oracle to perform this task, householders would first need to register to the oracle to associate their microgeneration equipment with their wallet address. During this process the oracle would also perform a quality assurance check to ensure their equipment was installed by a registered installer and has been certified. It would do this by checking scheme's such as the Microgeneration Certification Scheme [5].

Each household supplier that trades on this platform must have a wallet on the blockchain which provides an address to identify that supplier on the network.

The trade balance of each participant on the platform is maintained by a smart contract known as the export registry, and the electricity trading is enabled through a smart contract called the market. In Fig.1, the selling household is represented as the supplier, while another participant that is looking to purchase electricity is called the purchaser.

\section{CONCLUSION}

As the uptake of microgeneration increases, there is a possibility to provide significantly more control to consumers on the grid. This paper explored one way this could be achieved through the development of a new peer-to-peer electricity trading platform.

\section{REFERENCES}

[1] Department of Energy \& Climate Change, "Updated energy and emissions projections 2015," vol. 947, no. November, pp. 1-51, 2015. [Online]. Available: https://www.gov.uk/government/publications/updated-energyand-emissions-projections-2015

[2] Department of Energy \& Climate Change, "Monthly Central Feed-in Tariff register statistics - Statistical data sets - GOV.UK," May 2016. [Online]. Available: https://www.gov.uk/government/statisticaldata-sets/monthly-central-feed-in-tariff-register-statistics

[3] National Grid, "Transmission Losses | National Grid," accessed: 16/06/2016. [Online]. Available: http://www2.nationalgrid.com/UK/Industry-information/Electricitysystem-operator-incentives/transmission-losses/

[4] Government Office for Science, "Distributed Ledger Technology: beyond block chain," vol. January, 2016. [Online]. Available: https://www.gov.uk/government/publications/distributedledger-technology-blackett-review

[5] The Microgeneration Certification Scheme, "Microgeneration Certification Scheme - Home," accessed: 17/06/2016. [Online]. Available: http://www.microgenerationcertification.org/ 